\title{
4
}

\section{PARTICIPANT-INDUCED ELICITATION IN DIGITAL ENVIRONMENTS}

\author{
Riitta Hänninen
}

In this chapter, I discuss participant-induced elicitation interview (PIE) in the light of two fieldwork cases focusing on Finnish lifestyle blogging and older adults as ICT users. Collaboration with the people participating in the research has been an essential part of ethnography since the method was first introduced in anthropology in the first half of the 20th century. Thus, in this sense PIE is all about going back to the basics of anthropological fieldwork in contemporary digital environments. Visual orientation is an important element in many ethnographic interview techniques. Nevertheless, I argue that rather than being restricted to photography, this interview method could be further developed in a way that can better take into account the participatory aspects of ethnographic inquiry regardless of the source of elicitation. Drawing on the experiences from my two fieldwork cases, I first introduce PIE as an interview-based research method and then highlight some of the key characteristics of elicitation.

By definition, elicitation refers to a process where something, such as a response, meaning, or answer, is evoked in or drawn out from an interviewee (CD 2019). PIE is based on photo-elicitation (Collier 1957; Harper 2002), where the interviewee is asked to take photographs dealing with the topics of the research (Bignante 2010; Epstein et al. 2006). This type of idea is also included in other visual interview methods, such as autodriving (Heisley and Levy 1991; Ford et al. 2017), reflexive photography (Amerson 2014; Harrington and Lindy 1999), and the photovoice technique (Liebenberg 2018), originally deriving from photonovella (Wang and Burris 1994). Alternatively, the researcher can also use photographs taken by someone else than the interviewee as a starting point for elicitation (Padgett et al. 2013; Chiozzi 1989). Photography has also been employed in other visual methods such as photo interview and photo-diary (Hurworth et al. 2005). All the interview methods or techniques mentioned above share two distinctive characteristics in the context of PIE: they are based 
on visual material either produced by the interviewee or introduced by the researcher, and they rely on the collaboration between the researcher and the person participating in the research.

The main idea of PIE is that, in addition to photography, there are in fact various other "sources" or points or reference available for elicitation (cf. Harper 2002), including film (Skjælaaen et al. 2018; Gross and Levenson 1995), drawings and artwork (Hogan 2015; Bagnoli 2009), 3D objects in public displays (Du et al. 2018), visually impaired people "watching" or listening to television (Dim et al. 2016), and, as in the two cases examined in this chapter, mobile phones (Symons Downs 2018; Kaufmann 2018) and other digital devices such as tablets, laptops, smart televisions, and even blog posts consisting of both text and visual materials (Hänninen 2018). In this light, I argue that almost anything can serve as a point of reference for PIE just as long as it conveys meaning and relevance to the person participating in the research under the premises of the study in question.

In terms of interviewees taking photographs themselves or just looking at photographs taken by someone else, both of my fieldwork experiences lie between these two approaches. In the case of lifestyle blogging, the photographs included in the blog posts were only part of the source of elicitation as text, too, plays a significant role in blogging. Most importantly, however, the blog posts were originally compiled by the bloggers, not as methodological tools, but for an entirely different purpose separate from the aims of the research. In this sense, the photographs and texts produced by bloggers resemble photo interview and photo-diary rather than the autodriving or photovoice techniques. Furthermore, in the case of older adults' everyday lives and digital technology, PIE was designed to address the actual use of various ICTs by looking into the devices and applications utilized by the interviewees and documenting this use through taking photographs. Thus, I argue that it is more accurate to describe these fields of research in terms of PIE than for example photo-elicitation or other visually oriented research methods.

The central idea of PIE as participant-induced elicitation is based on the active agency of the person collaborating with the researcher. Under the premises of the research, the interviewee creates something subjective and personal that can be further examined and developed together with the researcher (Harper 2002). Alternatively, it is also possible to use something already created by the person participating in the interview, or to come up with something entirely new and relevant in the context of a given fieldwork. While the source or technique utilized in elicitation may vary, it is the focus of the analysis and the idiosyncrasies of the object of research that should determine the method (Hänninen 2012).

Many previous studies in the context of PIE and other related research methods often address some kind of element of power or a question of social inequality. While PIE is well-suited to various kinds of social and cultural phenomena, it is especially useful in research associated with marginal groups or topics that are hidden from or transcend the Western conceptions of reality and thought (Milne and Muir 2019). In this sense, PIE shares an affinity with community-based participatory action research (PAR) in emphasizing the collaborative aspects of 
elicitation techniques (Liebenberg 2018). PIE can also be useful in digital and virtual contexts as it has the capacity to overcome many of the boundaries associated with for example online and offline environments (Hänninen 2018).

\section{PIE in the blogosphere - the case of Finnish lifestyle bloggers}

My research on the relationship between lifestyle bloggers and their readers took place within the Finnish blogosphere in autumn 2014 (interviewing eight bloggers), autumn 2015 (interviewing three bloggers), and autumn 2017 (interviewing 14 bloggers). The research data was based on extended online observation and a total of 25 interviews, including 23 women and two male bloggers aged between 18 and 50. Because the vast majority of lifestyle bloggers have traditionally been women, the interview data mainly consisted of female bloggers. The main language in the blogs Finnish, although in some instances the bloggers were also using English and Swedish, which is the second official language of Finland. There were also several expatriates among the interviewees, who did not physically live in Finland, but who blogged mainly in Finnish and/or under Finnish blog portals. (See also Hänninen 2018.)

In the case of lifestyle blogging, choosing elicitation (or blog elicitation interview (BEI), as I called it in this context instead of PIE), which is a more general term referring to the participatory aspects of elicitation, was based on necessity. Fairly soon after conducting the first couple of interviews in 2014, I discovered that, while the research data produced through traditional thematic interview was informative enough, there was something missing from it. Although the bloggers themselves did their best to explain their trade to me, the interpretative distance remained too great and "the ontology of the blogosphere", by which I refer to the digital and virtual qualities of blogging, was not truly reflected in the interviews.

I invited the interviewees to choose two to four blog posts that they considered important for themselves as lifestyle bloggers and asked them to contemplate on what these blog posts were all about and why they had chosen these particular posts for our discussion (Hänninen 2018). While the majority of the bloggers were happy to do this, and some of them even emailed me a list of their blog posts of choice so that I could get acquainted with them before our interview session, there were a handful of interviewees who did not find this kind of "pre-assignment" particularly engaging. Some of them did not understand what they were supposed to do, while others could not find the time in their schedules to choose blog posts from their extensive archives. However, in practice this did not pose a big problem, as we could carry out this part of the interview together usually at the beginning of each elicitation interview and work our way from there. In fact, even the majority of bloggers who had chosen their favourite blog posts beforehand found more examples as the interview proceeded and thus added new material to their original lists. 
The main problem with using traditional thematic interview in the context of lifestyle blogging, which lies between online and offline environments, seemed to boil down to the multimodality of lifestyle blogging as a social media phenomenon. With the help of traditional thematic interview, it was difficult to grasp all the idiosyncrasies of the online environment through only talking about them without any practical reference to the blogosphere itself. PIE provided here the necessary ethnographic twist to overcome this problem and to carry out the fieldwork using a research method that was better equipped to deal with multimodality. It was also apparent that the fluctuating boundary between the online and offline spheres of social reality needed further methodological support to be better taken into account in the context of lifestyle blogging.

\section{Older adults using digital technology}

The fieldwork focusing on older adults and the role of digital technology in their everyday lives produced 22 elicitation interviews, including one interview conducted with an elderly couple. The data gathering took place in Central Finland in November and December 2018, and the age of the interviewees ranged between 57 and 89. Fourteen of the older adults participating in the research were female and nine were male. In this fieldwork, the purpose of PIE was again to deepen the traditional thematic interview in order to gain a better understanding on older adults' views regarding digital technology in their everyday lives and to see first-hand how they actually used or did not use digital technology on a daily basis.

The older adults were asked to contemplate on their use of digital technology and to come up with two to four examples highlighting their personal relationship with ICTs. The general reception towards this pre-assignment was ambivalent. While approximately half of the participants did choose some examples to cater for the research, it became apparent that the concept of digital technology was fluid among the older adults especially in terms of how they defined themselves as ICT users. Some regarded themselves as experienced and confident with digital technology, while others insisted that they knew almost nothing about it. They were self-conscious about anything to do with digital technology, including the preassignment.

In this context, PIE provided an easy and low-maintenance access to the actual use of devices ranging from ordinary mobile phones to smartphones, tablet computers, laptops, and smart televisions, and allowed me and my colleague ${ }^{1}$ assisting me with the fieldwork to become familiar with the pros and cons involved with ICTs in practice. Of course, not all the older adults participating in the research had smartphones at their disposal or used all the devices mentioned above. However, this did not pose a problem during the fieldwork as PIE could be adjusted according to the personal preferences of the interviewee. 


\section{Getting into the field - breaking the ice}

PIE can lower the threshold to discuss one's daily life and thus enhance the dialogue between the researcher and the person participating in the research by serving as an icebreaker at the beginning of the interview (Kaufmann 2018; Pink et al. 2016; Harper 2002). However, there are multiple reasons why establishing a safe, confidential, and inspiring atmosphere, which can be regarded as the basic elements of a successful interview, can at times prove difficult. For example, the interviewee can be confused about his or her role in the research, or as in Hanna's case in the lifestyle blogging study, the reason was that she felt that she had not been "a very good blogger" as she had not been posting all that much for a while:

I: [...] I just haven't had the time although I would've liked to.

R: That's okay. We can just pick a post at random. Let's take this one from your first year [of blogging].

I: Oh, that one, that's just one of those. There's really nothing to it. [...] I blogged a lot that year, 355 blog posts so nearly every day.

R: Okay, let's take another one. How about this post [a photo challenge]? This looks interesting.

I: That's actually a series of posts that has been circulating around [the blogosphere]. I've been doing it for the past five years. Every month, on the 14th of the month, I take a picture of the same place at the same time and then post it online. It's a kind of collage on how the world has changed between the photos. I've been sending this challenge to other bloggers and that's why it [the blog post] has spread around [the social media]. I now notice that it's my sixth year starting.

The role of PIE as an icebreaker is based on its emphasis on creating trust in the researcher (Hurworth et al. 2005) as well as on the personal and subjective interests of the interviewee. In Hanna's case, discussing the photographs she had taken over the past five years provided the interviewee with a positive point of reference as a lifestyle blogger and made her feel comfortable during the interview. It was also common among both lifestyle bloggers and older adults using digital technology that PIE evoked enthusiasm in the interviewees to show me around in their "digital everyday lives". In the context of lifestyle blogging, this proved to be a very valuable aspect as it opened up a possibility to become familiar with the strong multimodal side of lifestyle blogging and to visit all the other platforms actively managed by the bloggers in social media, ranging from the comment fields of the blogs to Facebook, Instagram, YouTube, and Snapchat. PIE also highlighted the often-blurred line between online and offline worlds in social media (which will be discussed further in the next subchapter) and promoted discussion on, for example, the privacy issues related to the Internet.

Elicitation provides interviewees with an important starting point, or a visual reference (Wiles et al. 2013) while thinking back about their everyday lives (Hänninen 2018; Aroldi and Vittadini 2015). As Bukowski and Buetow (2011; 
Padgett et al. 2013) argue, photographs can make the invisible visible by evoking feelings, memories, and thoughts that require verbalization to be accessible to the researcher. Visual stimuli can also enhance sensory awareness and reinforce reflexivity (Harris and Guillemin 2012). Blogs often consist of all the blog posts published by the blogger, which can sometimes stretch back over ten years or more, depending on the blogging history of a given blogger. The first fieldwork also highlights the comparative attributes of PIE by focusing the discussion on the temporal aspects of lifestyle blogging - what blogging used to be in the early years of the trade over ten years ago in comparison with contemporary social media. It also underlines the changes that have occurred in the blogosphere in recent years, such as commercialization, and the ways these transitions have affected bloggers as social media influencers.

Getting the chance to be shown around in a blog thanks to elicitation deepens the understanding provided by thematic interview. At the same time, however, PIE caters to another practical problem evident especially in the case of older adults as ICT users. During our fieldwork, I noticed that it was not always easy for the senior people to grasp what was meant by digital technology in general. This did not mean that they would have had insufficient knowledge regarding ICTs, or that we as researchers would have been interested in ranking the interviewees in terms of their dexterity in digital technology. Instead, some of the senior persons participating in the research were concerned about whether they knew enough to be eligible for the interviews in the first place. The function served by PIE in these kinds of situations was firstly to emphasize the subjective stance of the fieldwork and focus on the ways the interviewees themselves acted as ICT users in their everyday lives. This was possible by looking into the devices and applications the older adults used on a daily basis together with them. Secondly, it was also evident that PIE enhanced the thematic interviews by giving the interviewees a tool to remember and review all the mobile applications at their disposal, as shown in Matilda's, 64, interview account:

R: We've already discussed some of the apps, but I can see that you have the 112 [the Finnish emergency response center] app on your phone as well.

I: Yes, it's the best. I've recommended it to everybody with a smartphone. There have been a couple of times I've had to call an ambulance to our summer cottage. They [the ambulance crew] can see from the application, or one time they all of a sudden asked me, that there was a gate there and whether they could drive straight to the yard. The first time I was just baffled about how they can see everything from it [the 112 app]. I spend a lot of time in the woods by myself [picking wild berries and mushrooms, which is a common outdoor activity in Finland], so if something should happen to me, they would find me $[\ldots]$

R: [...] I can see that you have the Yle Areena [online platform for the public service media company in Finland] app here as well. [...] Do you watch television on your phone? 
I: Yes, sometimes in the summer cottage, but it's so difficult that I've shared the phone's connection to the tablet, because it has a bigger screen.

In the previous citation, there are several examples of the interviewee using digital technology that she had not mentioned before, such as the 112 application I noticed on Matilda's smartphone. We also discussed watching television on the phone and sharing the Internet connection from a phone to a tablet - all new themes and digital skills evoked by PIE through remembering and remembrance (cf. Hurworth 2003). Furthermore, as Collier (1979) has pointed out, a visual source of elicitation produce more detailed information compared to, for example, traditional thematic interview, which is based solely on conversation. These so-called "verbal interviews" can also become unproductive more quickly than interviews based on PIE. The reason for this is that visual points of reference prevent difficulties associated with communication and promote fluency of dialogue between the researcher and the person participating in the study.

Discussing the devices and applications together with the interviewees opened room for fresh insight for both the researcher and the older adults participating in the research. Furthermore, as there was no observation involved in this fieldwork, the elicitation technique was the only comparative medium through which it was possible to reflect on the difference between how the older adults described their use of digital technology and the ways they actually used it. As Hurworth et al. (2005) argue, interview techniques based on elicitation promote multi-method triangulation and thus enhance the validity and reliability of the research.

\section{The transcendent aspects of PIE}

In the context of lifestyle blogging, one of my main research questions focused on understanding the role of lifestyle blogging in the everyday lives of the bloggers. I was interested in finding out what kinds of boundaries existed between online and offline environments and discovered through PIE that, rather than describing the boundaries as such, I should instead focus on the reasons why, in fact, they exist in the contemporary blogosphere. If the online world is as discernible an element of everyday life as Hine (2015) quite accurately points out, why is it important for lifestyle bloggers to maintain a divide between the offline and online environments?

One explanation (Long and Wilhoit 2018; Abidin 2014) emphasizes the significance of privacy and safety issues in the expanding blogosphere. As lifestyle blogging has grown from a personal, diary-like hobby into a multi-million advertising business, the number of readers in contemporary lifestyle blogs, too, have increased (Hänninen 2015). Making one's everyday life less open to scrutiny and drawing a line between online and offline and consequently public and private has become, as Ellen points out in her interview account, an indispensable part of the trade: 
When your children grow older and are no longer babies, you start to think whether you can blog about somebody else's life. [...] My relatives of course want to know how the kids are doing, but I've noticed in other blogs as well that children's faces are not shown in the photos anymore. Instead, the pictures are turning unidentifiable.

In Ellen's interview, it was the blurred faces of her children, that evoked the discussion on the boundaries between public and private. The unidentifiable faces provided a visual anomaly that was irregular enough in comparison with other photographs without the blurring effect to stand out as something worth discussing in the context of the interview. Thus, PIE had the ability to highlight the oftenartificial boundaries between the online and offline spheres of everyday life and even transcend them (Hänninen 2018; Harris 2008; Jenkings et al. 2008). In the context of older adults, dealing with the embeddedness of daily ICT use was often associated with previously discussed issues such as remembering and remembrance, but also with "transcending the mundane" or self-evident aspects of digital technology.

Furthermore, in the case of lifestyle blogging, PIE played an important role in supporting the multi-sited aspects of the ethnographic field of research by giving the researcher access to the other social media platforms used by the lifestyle bloggers. Being shown around in the blog of an interviewee held an important temporal aspect to it as it made it possible to dive into the person's blogging archives and become familiar with their blogging history. The method deepened my understanding of lifestyle blogging as a whole through highlighting the integration of social media platforms made use of and developed by bloggers on a daily basis.

In the research on older adults using ICTs, it was important to be able to see first-hand what kinds of devices were used and to flexibly discuss all kinds of applications, platforms, and digital services relevant to the interviewees. Using mobile or smartphones, tablet computers, and laptops as a starting point was easy, because these devices were already "there": in the hand of the senior person answering the front door, on the kitchen table at their home, or ringing in their coat pocket if we met in a café for the interview. Even in cases where the senior person did not find him/herself particularly skilful with ICTs or did not own a smartphone, for example, the devices they did use acted as icebreakers informing me as a researcher about the difficulties, fears, and concerns related to digital technology.

As Harper (2002) points out, it is not necessary to restrict the elicitation-based interview method to professional or academic photography, art photographs, or photographs taken by the person participating in the research. The form of the visual representation is secondary to the relationship between the source of PIE and the cultural and social significance it bestows upon the phenomenon under study (Harper 2001; Chiozzi 1989). Although PIE is predominantly a visual research 
method, the main focus of the technique lies in the participative collaboration between the researcher and the interviewee. In fact, it can be argued that PIE is capable of transcending the visual by transforming photographs and other similar material into self-reflective discussion and text (Hurworth 2003).

\section{Creating something new through collaboration}

Unlike community-based participatory action research (PAR), which seeks empowerment on a communal level (Liebenberg 2018; Wang and Burris 1997), PIE focuses on individualized interviews by looking at visual objects of shared interest (Padgett et al. 2013; Lapenta 2011; Harper 2002). The main idea of PIE draws on the active agency of the person collaborating with the researcher. Although the source of the elicitation can vary, the participatory aspect of PIE remains the same: something new is created through the collaboration between the researcher and the person participating in the research for the purposes of the study.

PIE is a useful interview technique especially because it resembles the practices of social (and digital) sharing. It allows the interviewer and interviewees to examine and process the phenomena or topic of research together and reach a negotiated interpretation (Hurworth et al. 2005). The interviewee is encouraged to challenge the preconceptions of the interviewer, provide unprecedented perspectives to the discussion, and experiment with different kinds of ideas. In practice, this means that the focus of the method is in the ethnographic research tradition based on "the native's point of view" (Geertz 1973) rather than being driven by a priori theory or a concept.

Although PIE involves a very different take on the community empowerment aspect of PAR, PIE, too, can make an impact among the people participating in the research through increasing self-reflection. In the case of the older adults and digital technology, some of the interviewees found out that they could use WhatsApp for other purposes than only communicating with their family members and decided to establish new groups based on their hobbies and other interests. Similarly, one of the lifestyle bloggers picked up the methodological idea of choosing blog posts that have been important to her over the years and wrote a lengthy post about it to her readers. The interviewees were not encouraged or asked to do so, but they wanted to act upon the self-reflexive process initiated by their participation in the research project.

In methodological terms, PIE is often, although not necessarily, accompanied with traditional thematic interview. In this context, the function of PIE is to extend the scope of inquiry and to deepen the understanding regarding the topic of research through collaboration with the interviewee. In the two fieldwork cases discussed in this chapter, the elicitation usually took place at the beginning of the interview, but it can be carried out at any stage of the discussion. The reason for this kind of arrangement was that PIE is well suited for breaking the 
ice, and it often got the conversation going before I had the opportunity to ask any questions. The traditional list of semi-structured questions characteristic to thematic interview can at first seem opposite to the more visually oriented and collaborative PIE. On the contrary, however, it also serves an important function in the process as it provides the interview with an overall structure by keeping the researcher in check of the things that were initially the focus of the study and the new ideas and perspectives brought into play by the person participating in the research.

PIE has a tendency to produce longer and more detailed interviews in comparison with other types of techniques that are not based on a visual reference (Hurworth et al. 2005; Collier 1979). In the context of lifestyle blogging, the difference between the eight thematic interviews I conducted at the first stages of my fieldwork and PIE was very clear. The things that I found lacking in the thematic interviews were associated especially with the need of a concrete point of reference - both visual and otherwise - to the actual practices involved with lifestyle blogging. The bloggers participating in the research were struggling to find a personal perspective to their trade and the role it played in their everyday lives. Furthermore, as the blogs were left in the background of our discussions, the three-way connection between the researcher, the blogger, and blogging weakened, which led to a sense of "interpretative distance" during the first steps of the fieldwork. Once the missing point of reference was established by making blog posts the basis of the interviews, it became easier for the bloggers to identify themselves with the topic of the research. The need for a collaborative element that would break the ice and help the interviewees to make the topic of the research their own was also evident among the elderly ICT users, who found PIE useful especially as a tool for remembering and remembrance.

\section{Conclusions}

In anthropological terms, the main contribution of PIE to ethnography is that it reintroduces the idea of collaboration into fieldwork by tapping into the participatory aspects of the interview method and using collaboration simultaneously to both broaden and deepen the scope of ethnographic inquiry. In this chapter, I have argued that PIE can, in fact, be based on various other sources of elicitation than only photographs. The main idea of the method is not related to photography as such, but rather the active participation of the interviewee and his or her collaboration with the researcher. Thus, the cultural and social significance of the object that is applied as a starting point of PIE outweigh the form of the source of elicitation, be it visual or otherwise.

Nevertheless, it is clear that PIE is especially suitable to deal with visual sources of elicitation characteristic to social media. In this context, I argue that discussing pictures related to, for example, blog posts can in fact transcend the visual realm of social reality and transform photographs into a textual format. PIE cannot replace traditional visual analysis, but it provides an alternative to it by focusing on the 
interpretations and meanings evoked by the visual research material. Transcendence is also at play in contexts where PIE, following the daily lives and experiences of the people participating in the research, moves across the often-arbitrary boundaries between the offline and online environments characteristic to both lifestyle blogging and older adults using ICTs.

PIE can serve as an icebreaker in situations where getting into the field has proved difficult through focusing on the personal life of the interviewee. It has the capacity to establish trust in a new situation, where it supports the needs of collaboration. PIE also serves a very specific sensitizing function in interviews. Similarly to the idea of sensitizing concepts (Faulkner 2009), where the researcher introduces in the interview concepts that she has adopted from the persons participating in the research, elicitation creates a common ground between the researcher and the interviewee by emphasizing the significance of the interviewee's everyday life practices as a starting point of discussion. PIE also contributes to remembering things better either by recalling things as opposed to forgetting, or in more comprehensive terms, by evoking memories from the past. In this sense, it can both broaden and deepen the scope of inquiry and open up new perspectives beyond the initial focus of the study.

PIE is an intuitive research method, which makes it approachable to the person participating in the research. In the context of lifestyle blogging, this was reflected especially in the cases where the bloggers were showing me around in their blogs while at the same time discussing the significance of blogging in their everyday lives. Similarly, among the older adults using digital technology, it was not the device, such as a mobile phone or a laptop, in itself that proved important during the course of the interviews, but rather the personal lives of the interviewees opening up through the devices. In this sense, I argue that PIE resembles social and digital sharing, which allows the researcher and the person participating in the research to explore the topic of the research together in dialogue.

\section{Note}

1 I wish to thank research assistant Raija Luostari for her help while organizing and implementing our fieldwork from plan to practice. I also thank adjunct professors Helena Hirvonen, Sakari Taipale, and Mia Tammelin and PhD students Antti Hämäläinen and Joonas Karhinen from the Centre of Excellence in Research on Ageing and Care (CoE AgeCare), Department of Social Sciences and Philosophy, University of Jyväskylä, for their invaluable insight while planning the fieldwork.

\section{References}

Abidin, C. 2014. "Privacy for profit: Commodifying privacy in lifestyle blogging". Selected Papers of Internet Research 15. The 15th Annual Meeting of the Association of Internet Researchers. http://spir.aoir.org/index.php/spir/article/view/918

Amerson, R. 2014. "Reflexive photography: An alternative method for documenting the learning process of cultural competence". Journal of Transcultural Nursing 25 (2): 202-210. 
Aroldi, P., and N. Vittadini. 2015. "Audiences as socio-technical actors: The 'styles' of social network site users". In Revitalising Audience Research. Innovation in European Audience Research, 195-215, edited by F. Zeller, C. Ponte, and B. O’Neill. New York: Routledge.

Bagnoli, A. 2009. "Beyond the standard interview: The use of graphic elicitation and artsbased methods". Qualitative Research 9 (5): 547-570.

Bignante, E. 2010. "The use of photo-elicitation in field research. Exploring Maasai representations and use of natural resources". Echo Géo 11. https://echogeo.revues.org/11622

Bukowski, K., and Buetow, S. 2011. "Making the invisible visible: A photovoice exploration of homeless women's health and lives in Central Auckland". Social Science \& Medicine (72): 739-746. doi:10.1016/j.socscimed.2010.11.029

CD (Cambridge Dictionary). 2019. "Elicitation". https://dictionary.cambridge.org/dictiona ry/english/elicit

Chiozzi, P. 1989. "Photography and anthropological research: three case studies". Visual Sociology (42): 43-50.

Collier, J. 1957. "Photography in anthropology: A report on two experiments". American Anthropologist (59): 843-859.

Collier, J. 1979. "Visual anthropology". In Images of Information. Still Photography in Social Sciences, 271-282, edited by J. Wagner. Beverly Hills, California: Sage.

Dim, N. K., C. Silpasuwanchai, S. Sarcar, and X. Ren. 2016. "Designing mid-air TV gestures for blind people using user- and choice-based elicitation approaches". DIS 2016, June 4-8, 2016, Brisbane, Australia. doi:10.1145/2901790.2901834

Du, G., A. Dagbelo, C. Kray, and M. Painho. 2018. "Gestural interaction with 3d objects shown on public displays: An elicitation study". Interaction Design and Architecture(s) Journal (38): 184-202.

Epstein, I., B. Stevens, P. McKeever, and S. Baruchel. 2006. "Photo elicitation interview (PEI): Using photos to elicit children's perspectives". International Journal of Qualitative Methods 5 (3): 1-11.

Ford, K., L. Bray, T. Water, A. Dickinson, J. Arnott, and B. Carter. 2017. "Auto-driven photo elicitation interviews in research with children: Ethical and practical considerations". Comprehensive Child and Adolescent Nursing, 40 (2): 111-125.

Faulkner, R. 2009. "Improvising on sensitizing concepts". In Ethnographies Revisited: Conceptual Reflections from the Field, 79-91, edited by A. Puddephatt, W. Shaffir, and S. Kleinknecht. New York: Routledge.

Geertz, C. 1973. Local Knowledge: Further Essays in Interpretive Anthropology. New York: Basic Books.

Gross, J., and R. Levenson. 1995. "Emotion elicitation using films". Cognition and Emotion 9 (1): 87-108.

Harper, D. 2001. Changing Works: Visions of a Lost Agriculture. Chicago: University of Chicago Press.

Harper, D. 2002. "Talking about pictures - a case for photo-elicitation". Visual Studies 17 (1): $13-26$.

Harrington, C., and I. Lindy. 1999. "The use of reflexive photography in the study of the freshman year experience". Journal of College Student Retention 1 (1): 13-22.

Harris, A. 2008. "Young women, late modern politics, and the participatory possibilities of online cultures". Journal of Youth Studies 11 (5): 481-495.

Harris, A., and M. Guillemin. 2012. "Developing sensory awareness in qualitative interviewing: A portal into the otherwise unexplored". Qualitative Health Research 22 (5): 689-699.

Heisley, D., and S. Levy. 1991. "Autodriving: A photoelicitation technique". Journal of Consumer Research (18): 257-272. 
Hine, C. 2015. Ethnography for the Internet Embedded, Embodied and Everyday. London: Bloomsbury.

Hurworth, R. 2003. "Photo-interviewing for research". Social Research UPDATE 40. http:// sru.soc.surrey.ac.uk/SRU40.PDF

Hurworth, R., E. Clark, J. Martin, and S. Thomsen. 2005. "The use of photo-interviewing: three examples from health evaluation and research". Evaluation Journal of Australasia 4 (1-2): 52-62.

Hogan, S. 2015. "Mothers make art: Using participatory art to explore the transition to motherhood". Journal of Applied Arts \& Health 6 (1): 23-32.

Hänninen, R. 2018. "On the dark side of lifestyle blogging - the case of negative anonyms". WiderScreen 3. http://widerscreen.fi/numerot/2018-3/on-the-dark-side-of-lifestyle-blogg ing-the-case-of-negative-anonyms/

Hänninen, R. 2015. “'Is this an advertisement or a personal account?' - commercialisation of lifestyle blogs in Finland". Ethnologia Fennica (42): 54-69.

Hänninen, R. 2012. Puuterilumen lumo. Tutkimus lumilautailukulttuurista. Jyväskylä Studies in Humanities 191. Jyväskylä: University of Jyväskylä.

Jenkings, N., R. Woodward, and T. Winter. 2008. "The emergent production of analysis in photo elicitation: Pictures of military identity". Forum: Qualitative Social Research 9 (3). http://nbn-resolving.de/urn:nbn:de:0114-fqs0803309

Kaufmann, K. 2018: "The smartphone as a snapshot of its use: Mobile media elicitation in qualitative interviews". Mobile Media \& Communication 6 (2): 233-246.

Lapenta, F. 2011. "Some theoretical and methodological views of photo-elicitation". In Sage Handbook of Visual Research Methods, 201-213, edited by E. Margolis and L. Pauwells. Thousand Oaks: Sage.

Liebenberg, L. 2018. "Thinking critically about photovoice: Achieving empowerment and social change”. International Journal of Qualitative Methods (17): 1-9. doi:10.1177/1609406918757631

Long, Z., and E. Wilhoit. 2018. "Disciplined freedom, branded authenticity, and dependable independence: How tensions enact flexibility in lifestyle blogging careers". Journal of Applied Communication Research 46 (3): 368-387.

Milne, E-J., and R. Muir. 2019. "Photovoice: A critical introduction". In The SAGE Handbook of Visual Research Methods, 282-296, edited by L. Pauwells and D. Mannay. London: Sage.

Padgett, D., B. Smith, K-S. Derejko, B. Henwood, and E. Tiderington. 2013. "A picture is worth ...? Photo elicitation interviewing with formerly homeless adults". Qualitative Health Research 23 (11): 1435-1444.

Pink, S., H. Horst, J. Postill, and L. Hjorth. 2016. Digital Ethnography: Principles and Practice. London: Sage.

Skjælaaen, G., A. Lindseth Bygdås, and A. Landsverk Hagen. 2018. "Visual inquiry: Exploring embodied organizational practices by collaborative film-elicitation". Journal of Management Inquiry 1-17. doi:10.1177/1056492618778138

Symons Downs, D. 2019. "Beliefs about using smartphones for health behavior change: An elicitation study with overweight and obese rural women". Journal of Technology in Behavioral Science 4 (1): 33-41.

Wang, C., and M. A. Burris. 1994. "Empowerment through photo novella: Portraits of participation”. Health Education Quarterly 21 (2): 171-186.

Wiles, R., A. Bengry-Howell, G. Crow, and M. Nind. 2013. "But is it innovation?: The development of novel methodological approaches in qualitative research". Methodological Innovations Online 8, 18-33. 